\title{
Teeth Retention, Prosthetic Status and Need among a Group of Elderly in Nigeria
}

\author{
Arigbede Abiodun Olabisi ${ }^{1 *}$, and Chukuwuma Emmanuel Ifeanyi ${ }^{2}$ \\ ${ }^{1}$ Department of Restorative Dentistry, Faculty of Dentistry, College of Health Sciences, University of Port Harcourt, Nigeria \\ ${ }^{2}$ Department of Restorative Dentistry, University of Port Harcourt Teaching Hospital, Nigeria
}

\begin{abstract}
Background: Missing teeth without prosthetic replacement had been linked to reduced quality of life in elderly population. Data on teeth retention, prosthetic status and needs of elderly population is rare in our environment.

Aim: This study was designed to assess teeth retention, prosthetic status and needs among elderly patients attending our dental centre.

Methods: This cross-sectional study was conducted among elderly patients, 65 years and above attending Dental Centre of University of Port Harcourt Teaching Hospital using structured questionnaire and clinical examination. The clinical examination was conducted using WHO criteria. The questionnaire items include socio-demographic variables, dental clinic visit behavior and history of pain, chewing difficulty, denture wearing, systemic illness and medication. Teeth present and those indicated for extractions were charted. The prosthetic status and needs were also recorded. Chi Square was used to determine the relationship between two variables.

Results: There were 104 respondents out of which 53 (51.0\%) were males. The mean age was 71.5years $( \pm 6.1)$. About half (49.0\%) had not seen a dentist within the last five years. About $66 \%$ complained of dental pain and $67.6 \%$ had one systemic illness or the other. Majority of the patients $(90.1 \%)$ had 20 or more teeth in their mouth and $2(1.9 \%)$ had shortened dental arch. One respondent (1.0\%) had a 1-unit Bridge while $13.5 \%$ wear removable partial denture. Most of the respondents $(75.0 \%)$ needed prosthetic replacement.
\end{abstract}

Conclusion: There is a high prosthetic need and poor prosthetic status among the respondents.

Keywords: Elderly; Tooth loss; Prosthetic status; Prosthetic need; Nigeria

\section{Introduction}

As the age of the population increases, the number of adults with acute and chronic illnesses increases. The use of medication among this group of individuals also increases [1]. Many recent studies have shown that systemic diseases and their treatments may have an impact on oral health and vice versa [2]. For example, uncontrolled diabetes mellitus may cause oral infection and eventual tooth loss [3] while periodontal disease may give rise to pathogens which can become blood borne or aspirated into the lungs, and which may cause serious even life threatening consequences [2]. In addition, number of missing teeth has been found to be positively associated with a poorer general health status [4] and Chronic Periodontitis is a common cause of tooth loss among the elderly [5]. Tooth loss is an irreversible oral health problem with many and common consequences in the elderly population. $[6,7]$ Regrettably, older adults with chronic systemic diseases may not consider oral health much of a priority.

With the reported improvements in oral health in many countries, increasing number of people is retaining their teeth till old age [8]. The World Health Organization (WH0) expects $50 \%$ of elderly people to have at least 20 teeth in their mouths. $[9,10]$ Oral status and oral disease such as: edentulousness; caries; periodontitis; dry mouth among others is associated with reduced quality of life $[5,7,11]$. Apart from reduced oral functions and possible distorted aesthetics that may follow tooth loss [12-14], edentulous individuals may also suffer some psychological impairment [15]. In an investigation of patients receiving prosthetic treatments, most having lost their natural teeth several years before seeking replacement dentures, $45 \%$ admitted to having it difficult to accept the loss [15].

Oral rehabilitation is generally performed to maintain basic oral function [16]. Several reports on improvement in oral functions following prosthetic rehabilitation exist in the literature [7,17-18]. The proportion of prosthetic need is said to increase as age increases [7], but there is a varying proportion of elderly population who wear dentures as you move from one region to another $[19,20]$. Because of the reported decline in edentulism, the main focus in prosthodontics has shifted from provision of removable dentures particularly complete denture to fixed denture [8]. Prosthodontic interventions as well as maintenance and repair are by nature costly [8] but dentists must provide services for all segments of the population [21]. Medically compromised elderly are often labeled as 'poor candidates for dental treatment because they are unlikely to cooperate, find it difficult to get to the dental surgeries, or cannot pay professional charges [21]. One of the major challenges therefore, facing the dental profession today is maintaining oral health and functions into advance old age [2].

Epidemiological studies on oral health of the elderly are not common in Nigeria particularly as it relates to teeth retention, prosthetic status and need. We need to know how many of our elderly patients have chronic systemic diseases, how many are on medication, how many have dry mouth, and the number of them that wear and need denture. This data is needed for planning appropriate care for

*Corresponding author: Arigbede Abiodum Oblaisi, Department of Restorative Dentistry Faculty of Dentistry, College of Health Sciences, University of Port Harcourt, Port Harcourt, Rivers State, Nigeria, Tel: 1237055736436; E-mail: arisabbey@gmail.com

Received November 08, 2011; Accepted January 13, 2012; Published January 15,2012

Citation: Olabisi AA, Ifeanyi CE (2012) Teeth Retention, Prosthetic Status and Need among a Group of Elderly in Nigeria. Dentistry 2:117. doi:10.4172/2161 1122.1000117

Copyright: ( $) 2012$ Olabisi AA, et al. This is an open-access article distributed under the terms of the Creative Commons Attribution License, which permits unrestricted use, distribution, and reproduction in any medium, provided the original author and source are credited. 
this category of people and for monitoring the overall effects of oral care services in our population. This study aimed at investigating teeth retention and attitude to tooth extraction as well as prosthetic status and need among a group of Nigerian elderly from Niger Delta area of Nigeria.

\section{Materials and Methods}

This cross-sectional study was conducted using structured and open-ended anonymous questionnaire. The study was conducted among elderly patients 65 years and above attending the Dental Centre of University of port Harcourt Teaching Hospital. The questionnaire was self-administered to the elderly attending our centre. Patients who were less than 65 years and elderly patients who declined participation were excluded from the study.

The questionnaire sought for socio-demographic variables like age, sex and level of education. The questionnaire items also includes history of dental clinic behavior in the last five years, history of dental pain, chewing difficulty, history of systemic illness and medication, as well as history of dry mouth. The respondents were also requested to state how satisfy they are with their oral health. They were asked to indicate with respect to each question whether their response was 'yes', 'not sure' or 'no' In addition, respondents were requested to specify the systemic illness they were suffering from and to indicate whether they wear fixed or removable denture and whether these prostheses were satisfactory. In addition, the respondents were to indicate whether the dentures were for the upper, lower, or both arches. Finally, they were asked to assess their health if it is Excellent, V. Good, Good, Fair, or Poor.

The clinical examination was conducted by one of the authors using WHO prescribed guidelines. Assessment of prosthetic status and need was also done using the following codes described by WHO: Prosthetic status of $0=$ No prosthesis; $1=$ Bridge, $2=$ More than one Bridge, $3=$ Partial denture, $4=$ Both bridge(s) and partial denture, $5=$ Full removable denture, $9=$ Not recorded and for prosthetic need $(0=$ No prosthesis needed, $1=$ Need for one-unit prosthesis, $2=$ Need for multi-unit prosthesis, $3=$ Need for a combination of one-unit and/ or multi-unit prosthesis, $4=$ Need for full prosthesis (replacement of all teeth) $9=$ Not recorded). Teeth present and those indicated for extraction were charted and respondents having short dental arches were noted. Anonymity and confidentiality of the respondents were preserved. Convenience sampling technique was employed.

\section{Statistical Analysis}

The data were analyzed using SPSS package version 15.0. Chi square analysis was used to find out the relationship between self-reported oral health and self-reported systemic health. Level of significance was set at 0.05 .

\section{Results}

There were 104 respondents out of which 53 were males (51.0\%) and the remaining $51(49.0 \%)$ were females. The age range of the respondents was 65-88years and the mean was 71.5years $( \pm 6.1)$. Thirty-eight respondents (36.5\%) had post secondary education, 17 (16.3\%) had secondary education, $33(31.7 \%)$ had primary education and 16 respondents (15.4\%) had no former education. Half of the respondents (50.0\%) claimed that they had seen a dentist in the last five years, $66.3 \%$ complained of dental pain and 40 (38.5\%) complained of chewing difficulty (Table 1). Sixty-five respondents (67.6\%) had systemic illness. A breakdown of the illnesses showed that most of the respondents $(25.0 \%)$ claimed they had hypertension. This was followed by $13.5 \%$ who claimed they had a combination of Hypertension and Diabetes Mellitus (Figure 1). Fifty-four (80.6\%) of the 67 respondents who claimed they had systemic illness were on medication for these illnesses. Eleven respondents (10.6\%) had dry mouth, 88 (84.6\%) did not have while 4 (4.8\%) were not sure.

Forty-two respondents were satisfied with their oral health (40.4\%) while $50(48.1 \%)$ were not and twelve respondents (11.5\%) were not sure of their satisfaction. Four respondents (3.8) described their systemic health as poor, $40(38.5 \%)$ described it as fair, $37(35.6 \%)$ described it as good and $17(16.3 \%)$ were of the view that their systemic health was very good. Six respondents (5.8\%) however indicated that their systemic health was excellent. Chi Square test showed a significant relation between self-reported satisfaction with oral and systemic health $\left(X^{2}=25.332, \mathrm{p}=0.001\right)$.

Majority of the respondents $(66,63.5 \%)$ respondents had one tooth or the other charted for extraction. The number of teeth indicated for extraction ranges from 1-5, but the mean was $1.1( \pm 1.3)$. Most of the respondents, $42(63.6 \%)$ readily accepted the recommended extraction, $16(24.2 \%)$ were reluctant to accept the treatment while 8 (7.7\%) out rightly rejected the option. Twenty-six respondents (25.0\%) needed no prosthetic replacement and out of this number, 14 (13.5\%) had full complement of teeth and needed no extraction. Ninety four respondents $(90.1 \%)$ had 20 or more teeth in their mouth and $2(1.9 \%)$ had shortened dental arch. The mean number of teeth remaining in the mouth of the respondents after extraction was $27.5( \pm 5.1)$.

Only one respondent (1.0\%) wear 1 unit Bridge. No multiple unit Bridge was encountered and no full prosthesis was encountered. Fourteen respondents (13.5\%) were removable partial denture wearers (Figure 2). Out of the 14 wearing removable partial denture, $6(5.8 \%)$ wore upper removable acrylic denture, $6(5.8 \%)$ also wore lower removable acrylic denture while 2 respondents (1.9\%) wore a combination of upper and lower acrylic partial dentures. Three $(21.4 \%)$ of the removable partial denture wearers had unsatisfactory dentures. Regarding prosthetic need, 78 (75.0\%) respondents needed one form of prosthetic replacement or the other either in one or both arches.

\begin{tabular}{|l|l|l|l|}
\hline \multicolumn{1}{|c|}{ Questions } & Yes & Not sure & No \\
\hline $\begin{array}{l}\text { Have you been to a dentist in the last five } \\
\text { years? }\end{array}$ & $52(50.0 \%)$ & $1(1.0 \%)$ & $51(49.0 \%)$ \\
\hline Do you have dental pain? & $69(66.3 \%)$ & $1(1.0 \%)$ & $34(32.7)$ \\
\hline Do you have difficulty chewing? & $57(54.8 \%)$ & $7(6.7 \%)$ & $40(38.5 \%)$ \\
\hline
\end{tabular}

Table 1: Report on clinic attendance, oral pain and chewing difficulty experience.

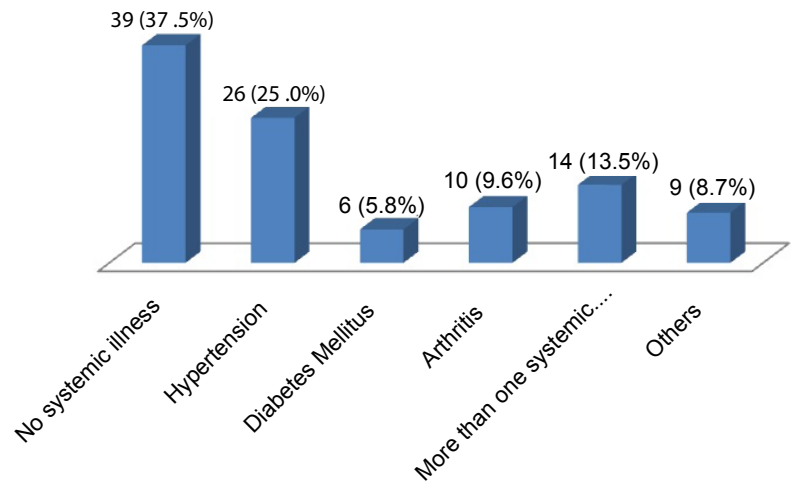

Figure 1: Distribution of systemic illnesses. 
Seventeen 1 unit restorations and twenty-two 1 unit restorations were needed in the upper and lower arches respectively. Thirty-three multiple units restorations were needed in the upper arch while 31 were required for the lower arch. In the upper arch, there was the need for a combination of one-unit and/ or multi-unit prosthesis in just three cases whereas; there was the need for such combination in the lower arch in five cases. Seventeen respondents needed one-unit prosthesis while 26 needed multi-unit prosthesis (Figure 3).

\section{Discussion}

There were $53(51.0 \%)$ males in this study. Most epidemiological studies on this subject usually reveal more female participants $[5,7,10]$. The mean age $71.5( \pm 6.1)$ years recorded in this study was close to that described by the WHO [9] for epidemiological studies involving the elderly. Regarding educational background, most of our patients were literate. Similar studies $[22,23]$ revealed that most of the subjects had not undergone any former education. About half of our respondents had not seen the dentist within the last five years. A similar behavioral pattern towards oral health care had previously been reported among this group of people [22-24]. This behaviour may explain why high unmet dental needs are often found in the elderly.

Our data showed that a varying percentage of the respondents had one oral complaint or the other. Bansal et al. [22] reported that $65 \%$ of their elderly patients presented with one oral complaint or the other out of which $28.7 \%$ was dental pain related. Oro-facial pain particularly those of dental origin is a very frequent reason for patients' attendance at the dental clinic [25]. Oral health (periodontal disease, chewing difficulty and so on) had been linked to the general well-

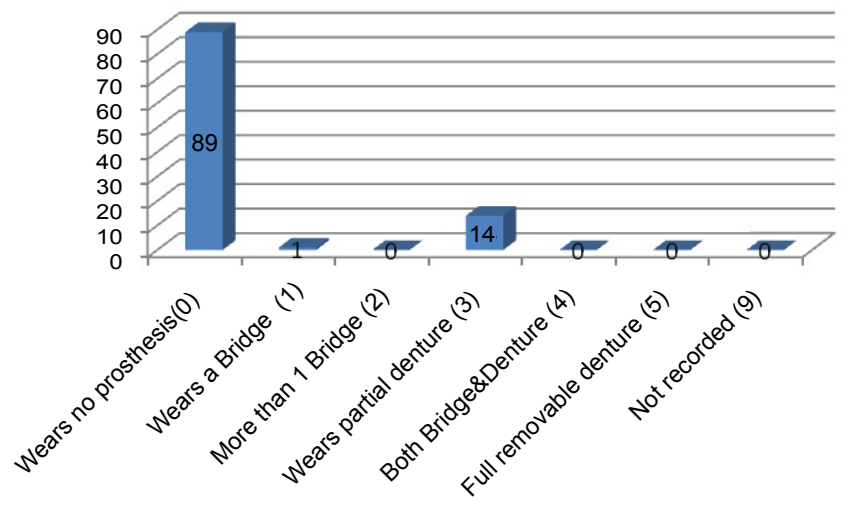

Figure 2: Prosthetic status of respondents $(n=104)$.

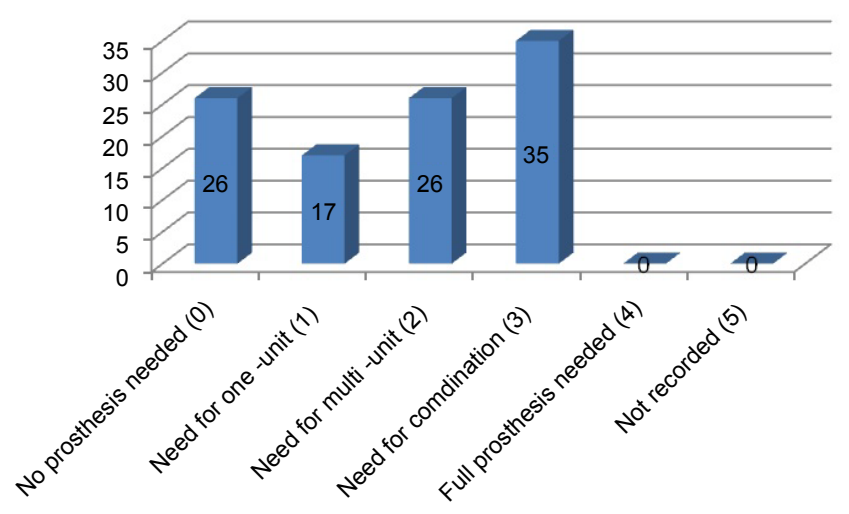

Figure 3: Prosthetic need of respondents $(n=104)$. being of patients [7]. A significant relationship was found between self-reported satisfaction with oral health and self-reported satisfaction with systemic health in this study $\left(X^{2}\right.$ test $\left.\mathrm{p}=0.001\right)$.

Evaluation of self-reported medical conditions of the subjects showed that Hypertension, Diabetic Mellitus and the combination of the above were the most common chronic systemic conditions among our subjects. A similar pattern was described by Bansal et al. [22], Dry mouth is said to be a common problem among the elderly causing a significant oropharyngeal disorders, pain and an impaired quality of life [26], but our findings suggest that this oral health condition was not a major oral health problem among our patients. Most of the respondents did not also rate their health highly. It is believed that as people live longer with significant chronic systemic diseases and as older individuals seek dental care, practitioners will increasingly encounter medically and functionally compromised patients [2]. These individuals may also be on medications which may further impart negatively on their oral health.

Request for denture, extraction and toothache - related complaints were among the most prominent reasons for seeking dental care in a previous study [27]. Most of our subjects needed one or more tooth extraction. Five per cent of the remaining teeth in the study by Levalainen et al. [19] were indicated for extraction. The report by Bansal et al. [22] also indicated that a considerable number of subjects had all the remaining teeth indicated for extraction. Only few of our respondents were reluctant to have tooth extraction where indicated. This may not be unrelated to the desire to have immediate relief from the hurting teeth.

Not a single case of edentulism was encountered in this study and 14 of our subjects had a full complement of teeth. In a similar study in Sri Lanka [28], 11 subjects had full teeth complement and $17 \%$ were edentulous. Increase in teeth retention and decline in edentulism among the elderly had been previously reported $[8,29]$ even in our environment $[30,31]$. The average number of teeth present in this study was 27.5 ( \pm 5.1 ). This was much higher than $22.8 \%$ reported by Bansal et al. [22] and $13.2 \%$ reported by Nevalainen et al. [19]. Similarly, the number of subjects with 20 or more natural teeth was much than $50 \%$ reported in a Chinese study [32] and 3/4 reported in an Indian study [22]. According to WHO target [9], 50\% of the elderly population should possess at least 20 teeth in their mouths. It has however been stated that the number of functional teeth in occlusion gives a more vivid picture of oral function than the number of teeth present in the oral cavity [32].

Clinical studies indicated that SDAs comprising intact anterior and premolar teeth (10 occluding pairs), appeared to have, in the long term, sufficient adaptive capacity to ensure adequate oral function in terms of chewing ability, aesthetics, stability of the dentition, temporomandibular joint (TMJ) function and functional habits $[33,34]$. Two (2.4\%) of our patients had SDA. This finding supports the previous finding by Sarita et al. [35]. Where most dentists in Tanzania likewise indicated that shorten dental arch was not a common finding in clinical practice.

Our data revealed a very poor prosthetic status in the respondents. The number of respondents wearing dental prosthesis is ridiculously low compare to data elsewhere. Poor socio-economic status, poor dental health education and the fact that health insurance scheme in Nigeria does not cover dental prosthesis may play a major role in this regard. Nevalainen et al. [19] reported that 53\% of their subjects were removable denture wearers and $45 \%$ wear fixed prostheses. In 
Citation: Olabisi AA, Ifeanyi CE (2012) Teeth Retention, Prosthetic Status and Need among a Group of Elderly in Nigeria. Dentistry 2:117. doi:10.4172/2161-1122.1000117

Page 4 of 4

UK [7], $31 \%$ of the elderly were reported to be denture wearers. More than $20 \%$ of existing dentures being used by the elderly were found to be defective in Singapore [36] while $21.4 \%$ of denture wearers in our study had unsatisfactory prosthesis. The percentage of respondents who needed prosthetic replacements in our study $(75.0 \%)$ was the same as that reported in a study in Hong Kong (75\%) and above the $60 \%$ that was reported in Thailand [7].

Our data shows a high unmet prosthetic need. This suggests poor oral health utilization among the respondents. There is a widespread agreement that missing teeth do not per se need prosthetic treatment but oral rehabilitation with dentures has long been advocated as effective measures in reducing the burden associated with toot loss, particularly among those who have experience considerable tooth loss [14]. The prosthetic need in the upper arch is almost the same as that required for the lower arch in the current study. In a Brazilian study, one-third of the elderly people presented a need for upper jaw prosthesis and more than half needed a lower jaw prosthesis. In Germany, $40.3 \%$ of the subjects needed no prosthesis, $30.7 \%$ needed FPD and 29.0\% needed RPD [37]. The same number of multiple units' prosthesis is needed for both the upper and lower jaw in this study while almost the same number of single unit prosthesis was required for the arches.

\section{Conclusion}

There was a high prosthetic need and poor prosthetic status among the respondents. The number of respondents with 20 or more natural teeth was satisfactory. Most of the respondents did not oppose extraction of non-functional teeth.

\section{References}

1. Niessen LC, Fedele DJ (2002) Aging successfully: oral health for the prime of life. Compend Contin Educ Dent 23: 4-11.

2. Holm-Pedersen P (2002) Gerodontology-status and new challenges. ActaStomatol Croat 36: 312.

3. Awartani $F$ (2009) Evaluation of the relationship between type 2 diabetes and periodontal disease. Odontolstomatol Trop 32: 33-39.

4. Lee HK, Lee KD, Merchant AT, Lee SK, Song KB, et al. (2010) More missing teeth are associated with poorer general health in the rural Korean elderly. Arch Gerontol Geriatr 50: 30-33.

5. Adeyemo WL, Oderinu HO, Oluseye SB, Taiwo OA, Akinwande JA (2008) Indications for extraction of permanent teeth in a Nigerian teaching hospital: a 16-year follow-up study. Nig Q J Hosp Med 18: 128-132.

6. McGrath C (2002) Oral health behind bars: a study of oral disease and its impact on the life quality of an older prison population. Gerodontology 19: 109114.

7. Kuo HC, Yang YH, Lai SK, Yap SF, Ho PS (2009) The Association between health-related quality of life and prosthetic status and prosthetic needs in Taiwanese adults. J Oral Rehabil 36: 217-225.

8. Carlsson GE, Omar R (2006) Trends in prosthodontics. Med Princ Pract 15: $167-179$

9. Joharji RM, Adenubi JO (2001) Prevention of pit and fissure caries using an antimicrobial varnish: 9 month clinical evaluation. J Dent 29: 247-254

10. Martins AM, Barreto SM, Pordeus IA (2008) [Factors associated to self perceived need of dental care among Brazilian elderly]. Rev SaudePublica 42: 487-496.

11. Arvidson-Fyrberg K (2002)When and how shall I plan dental and prosthetic treatment for the elderly? ActaStomatol Croat 36: 312.

12. Boretti G, Bickel M, Geering AH (1995) A review of masticatory ability and efficiency. J Prosthet Dent 74: 400-403.

13. Sheiham A, Steele JG, Marcenes W, Finch S, Walls AW (1999) The impact of oral health on stated ability to eat certain foods; findings from the National Diet and Nutrition Survey of Older People in Great Britain. Gerodontology 16: 11-20.

14. McGrath C, Bedi R (2002) Severe tooth loss among UK adults--who goes for oral rehabilitation? J Oral Rehabil 29: 240-244

15. Basker RM, Davenport JC (2002) Prosthetic treatment of the edentulous patient $\left(4^{\text {th }}\right.$ edn $)$, Blackwell Publishing, Oxford 21-30.

16. McMillan AS, Wong MC, Lo EC, Allen PF (2003) The impact of oral disease among the institutionalized and non-institutionalized elderly in Hong Kong. $J$ Oral Rehabil 30: 46-54.

17. Koshino H, Hirai T, Ishijima T, Tsukagoshi H, Ishigami T, et al. (2006) Quality of life and masticatory function in denture wearers. J Oral Rehabil 33: 323-329.

18. Anastassiadou V, Robin Heath M (2006) The effect of denture quality attributes on satisfaction and eating difficulties. Gerodontology 23: 23-32.

19. Nevalainen MJ, Narhi TO, Siukosaari P, Schmidt-Kaunisaho K, Ainamo A (2003) Prosthetic rehabilitation in the elderly inhabitants of Helsinki, Finland. J Oral Rehabil 23: 722-728.

20. Ferreira RC, de Magalhaes CS, Moreira AN (2008) Tooth loss, denture wearing and associated factors among an elderly institutionalised Brazilian population. Gerodontology 25: 168-178.

21. lacopino AM, Wathen WF (1994) A low-cost, portable removable prosthodontic treatment system for the compromised elderly. Dent Update 21: 166-172.

22. Bansal V, Sogi GM, Veeresha KL (2010) Assessment of oral health status and treatment needs of elders associated with elders' homes of Ambala division, Haryana, India. Indian J Dent Res 21: 244-247.

23. Goel P, Singh K, Kaur A, Verma M (2006) Oral healthcare for elderly: identifying the needs and feasible strategies for service provision. Indian J Dent Res 17 $11-21$.

24. Marino R (1994) Oral health of the elderly: reality, myth, and perspective. Bul Pan Am Health Organ 28: 202-210.

25. Ivana O, Nada G, Sanja S, Bozidar P, Irina F, et al. (2004) The prevalence and type of Pain in Dental patients. Acta Stomat Croat 38: 13-17

26. Turner MD, Ship JA (2007) Dry mouth and its effects on the oral health of elderly people. J Am Dent Assoc 138 Suppl: 15S-20S.

27. Razak IA, Ali MM (1988) Ethnic and sex variations in dental care utilization patterns in a group of Malaysian elderly. Gerodontology 7: 77-80.

28. Pallegedara C, Ekanayake $L$ (2005) Tooth loss, the wearing of dentures and associated factors in Sri Lankan older individuals. Gerodontology 22: 193-199.

29. Douglass CW, Watson AJ (2002) Future needs for fixed and removable partial dentures in the United States. J Prosthet Dent 87: 9-14.

30. Taiwo JO, Omokhodion F (2006) Pattern of tooth loss in an elderly population from Ibadan, Nigeria. Gerodontology 23: 117-122.

31. Arigbede AO, Dosumu OO (2007) Decline in complete dentures patients' turnout in dental schools: Experience at $\mathrm{UCH}$, Ibadan, Nigeria. Nigerian Med Pract 52: $60-63$

32. Lin HC, Corbet EF, Lo EC, Zhang HG (2001) Tooth loss, occluding pairs, and prosthetic status of Chinese adults. J Dent Res 80: 1491-1495.

33. Witter DJ, van Palenstein Helderman WH, Creugers NH, Kayser AF (1999) The shortened dental arch concept and its implications for oral health care. Community Dent Oral Epidemiol 27: 249-258.

34. Kanno T, Carlsson GE (2006) A review of the shortened dental arch concept focusing on the work by the Kayser/Nijmegen group. J Oral Rehabil 33: 850862.

35. Sarita PT, Witter DJ, Kreulen CM, Creugers NH (2003) The shortened dental arch concept--attitudes of dentists in Tanzania. Community Dent Ora Epidemiol 31: 111-115.

36. Soh G, Chong YH, Ong G (1992) Dental prosthetic status and needs of an elderly population living in long-term care facilities in Singapore. J Community Health 17: 175-181.

37. Walter MH, Wolf BH, Rieger C, Boening KW (2001) Prosthetic treatment need in a representative German sample J Oral Rehabil 28: 708-716. 